\title{
A Control Circuit Small Wind Turbines with Low Harmonic Distortion and Improved Power Factor
}

\author{
O. Carranza ${ }^{1}$, E. Figueres ${ }^{2}$, G. Garcerá ${ }^{2}$ and L. G. González ${ }^{3}$ \\ ${ }^{1}$ Professional School of Computation - National Polytechnic Institute \\ Av. Juan de Dios Bátiz S/N, 07738, D. F. (México) \\ Phone number:+52 5557296000 ext 52022, e-mail: ocarranzac@ipn.mx \\ ${ }^{2}$ Electronic Engineering Department - UPV \\ Camino de Vera S/N, 7F, 46022, Valencia (Spain) \\ Phone number:+34 963879606, e-mail: efiguere@eln.upv.es, ggarcera@eln.upv.es \\ ${ }^{3}$ Electronic and Communications Engineering Department - Andes University \\ Merida, (Venezuela) \\ Phone/Fax number:+34 963879606, e-mail: lgerardo@ula.ve
}

\begin{abstract}
This paper presents the application of average current mode control to reduce the $\mathrm{THD}_{\mathrm{i}}$ and increase the $\mathrm{PF}$ in a Three-Phase Boost Rectifier driving a small wind turbine. It is used as input stage of small wind turbines with permanent magnet synchronous generators operating at variable speed. The Boost Rectifier's output is connected to an inverter which feeds the energy to a distribution power grid. The operation in discontinuous conduction mode allows significantly reducing the Total Harmonic Distortion of the current in the small wind turbine. However, it is necessary to add an input filter so that the switching ripple doesn't arrive to the small wind turbine. It is evaluated the convenience of the current sensors placement in the DC side of the rectifier or at the output of the generator. The results demonstrate that it is better to place the sensors in the output of the generator, because it is achieved smaller $\mathrm{THD}_{\mathrm{i}}$ and higher PF.
\end{abstract}

\section{Key words}

Average Current Control, Boost Rectifier, Discontinuous Conduction Mode, Wind Turbines.

\section{Introduction}

A Wind Generation System (WGS) is constituted by an eolic turbine and an electrical generator. In small WGS it is preferred the use of Permanent Magnet Synchronous Generators (PMSG) operating at variable speed, so that both amplitude and frequency of the generator output voltage varies in a certain range, following the wind speed. Because of that, a power converter is needed to connect the WGS to a distribution power grid.

The simplest converter to process the WGS energy is the cascade association of a non controlled rectifier with a power inverter, which is connected to the grid and operates with both constant voltage and frequency.

With such a configuration, the harmonic distortion of the generator currents $\left(\mathrm{THD}_{\mathrm{i}}\right)$ is high, achieving the $30 \%$. Sometimes, a Boost DC-DC converter is used to maintain near constant the voltage at the input of the power inverter, in spite of the rectifier voltage reduction when the PMSG operates at low speeds. As a whole, the non controlled rectifier and the Boost DC-DC converter are known as Boost Rectifier, which can be also used to reduce the generator currents distortion [1]. Generally, a Boost Rectifier driving a PMSG operates in Continuous Conduction Mode (CCM) because of the large value of the generator inductances. Fig. 1 shows both current and voltage in one of the generator phases with a Boost Rectifier working in CCM. A THDi $\approx 21 \%$ has been reported, so that the power factor (PF) of the Boost Rectifier is low $(\mathrm{PF}=0.73)$. Moreover, the current harmonics produces torque harmonics in the PMSG, resulting in additional vibrations and increasing the maintenance needs.

An outstanding novelty of this work with regard to [1][3] is that both the voltage amplitude and frequency varies in a large operation range, which depends on the turbine speed.

As a result, both the power stage and the control loops of the Boost Rectifier must be carefully designed.

Average Current-Mode Control (ACC) is proposed to indirectly regulate the PMSG torque, because the generators currents are proportional to the electromagnetic torque. 

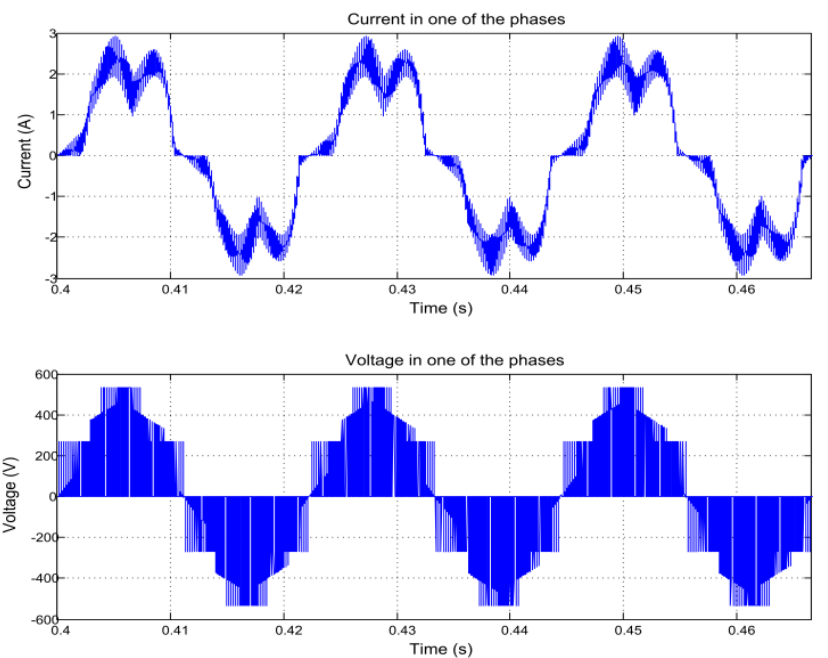

Fig. 1. Current and Voltage of one phase of a Three-Phase Boost Rectifier in CCM

The ACC principle is to measure the average current of the power inductor or some other current in a point where it is reflected the average current of the power inductor, so that it can be less sensible to the commutation noise in the measure of the current. ACC is suitable to implement a source of regulated current.

The influence, in terms of performance, of the current sensors placement (in the DC side or at the output of the generator) has been investigated, showing that a lower $\mathrm{THD}_{\mathrm{i}}$ results when the current is sensed at the output of the generator.

\section{Boost Rectifier in DCM}

Fig. 2 shows the scheme of the Three-Phase Boost Rectifier studied with the two points where the average current can be measured, and with the following values:

- Output Power of the generator: $\mathrm{P}=2 \mathrm{~kW}$

- Output Voltage of the rectifier: $\mathrm{V}_{0}=800 \mathrm{~V}$.

- output voltage range of the generator: $\mathrm{V}_{\mathrm{ab}}=104$ $416 \mathrm{~V}_{\mathrm{rms}}$

- Inductance of one phase of the generator: $\mathrm{L}_{\mathrm{ga}}, \mathrm{L}_{\mathrm{gb}}$, $\mathrm{L}_{\mathrm{gc}}=25 \mathrm{mH}$
- Resistance of one phase of the generator: $\mathrm{R}_{\mathrm{ga}}, \mathrm{R}_{\mathrm{gb}}$, $\mathrm{R}_{\mathrm{gc}}=5 \Omega$

- Number of poles: $\mathrm{n}_{\mathrm{p}}=12$

- Nominal Current: $\mathrm{I}_{\text {nom }}=4.87 \mathrm{~A}_{\mathrm{rms}}$

- Range of speeds of the generator: $\mathrm{n}_{\mathrm{m}}=150-600$ rpm

The circuit that is used for the analysis considers two phases, in the moment that the diodes of each one allow the rectification; Fig. 3 shows the equivalent circuit.

With this consideration, $\mathrm{L}_{\mathrm{g}}=2 \mathrm{~L}_{\mathrm{ga}}, \mathrm{R}_{\mathrm{Lg}}=2 \mathrm{R}_{\mathrm{Lga}}, \mathrm{L}=2 \mathrm{~L}_{\mathrm{a}}$, $\mathrm{R}_{\mathrm{L}}=2 \mathrm{R}_{\mathrm{La}}$ and $\mathrm{C}_{\mathrm{i}}=3 \mathrm{C}_{1} / 2 . \mathrm{V}_{\mathrm{g}}$ is the rectifier output voltage averaged in a complete period of rectification. The circuit is reduced to that shown by Fig. 4

\section{A. Boost Rectifier in DCM}

In order to work in discontinuous conduction mode (DCM) [4], condition (1) must be accomplished. This condition allows the design of $\mathrm{L}$ to operate in DCM in the whole range of PMSG speeds. D is the duty cycle, L is the equivalent Boost inductance, $K_{\text {crit }}$ allows to determine the conduction mode of the converter and $f_{s}$ is the switching frequency.

$$
\begin{gathered}
K=\frac{2 L P f_{s}}{V_{0}^{2}} \text { and } K_{\text {crit }}(D)=D(1-D)^{2} \\
K<K_{\text {crit }}(D) \text { for DCM }
\end{gathered}
$$

The duty cycle in DCM is obtained by means of (2)

$$
D=\frac{\left(2 V_{0}-v_{g}\right)+v_{g} \sqrt{1+\frac{8 V_{0} L f_{s}}{R_{L}^{2} P}\left(V_{0}-v_{g}\right)}}{V_{0}\left(\frac{2 v_{g}^{2}}{P R_{L}}-\frac{R_{L}}{L f_{s}}\right)}
$$

The maximum value of the Boost inductance $\left(\mathrm{L}_{\max }\right)$ is obtained from (2) and (3). For a switching frequency $\left(f_{s}\right)$ of $5 \mathrm{kHz}$, considering the generator speed range, it results $\mathrm{L}_{\max }=815.2 \mu \mathrm{H} . \mathrm{L}=750 \mu \mathrm{H}$ is selected, so that the Boost rectifier operates in DCM.

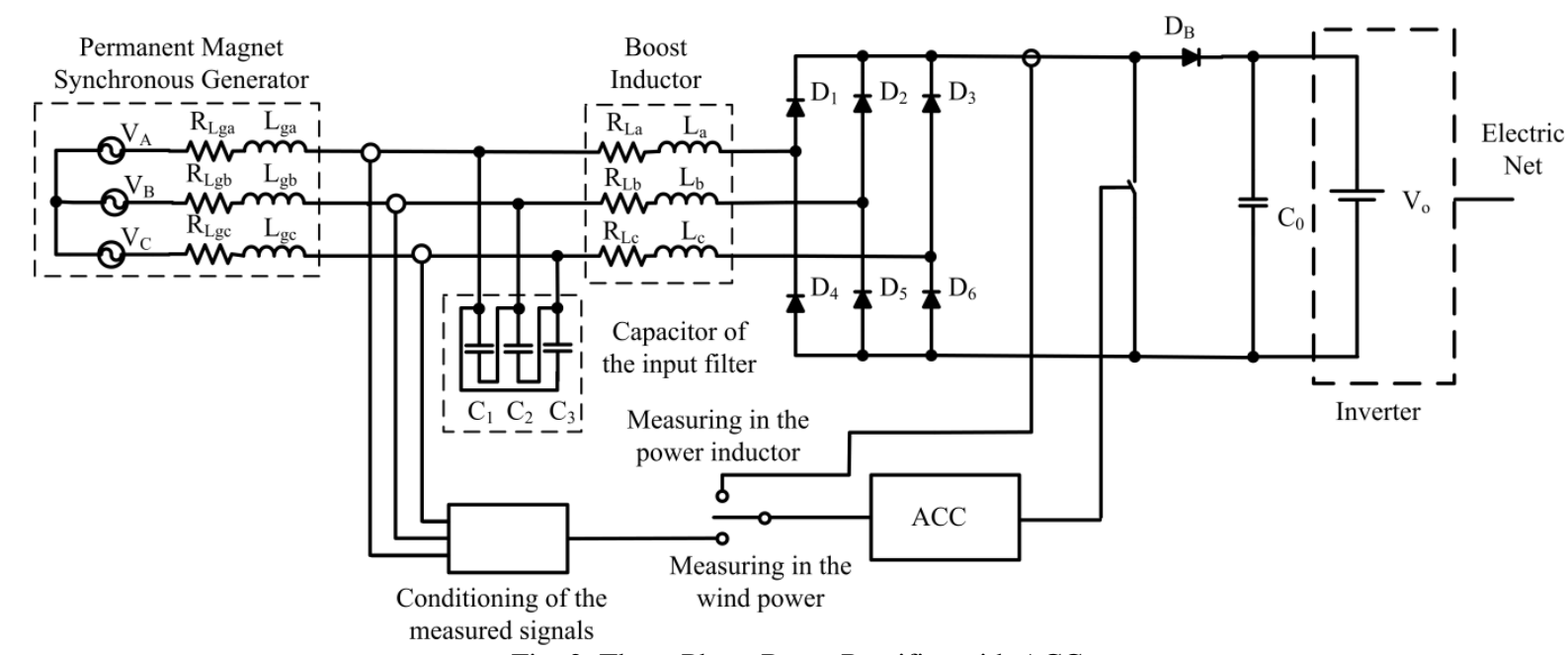

Fig. 2. Three-Phase Boost Rectifier with ACC 


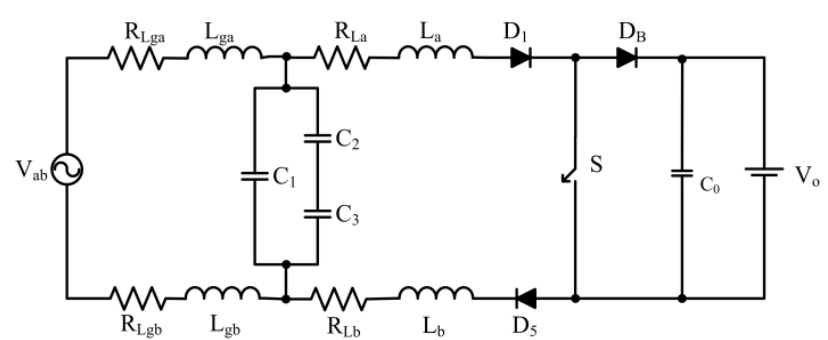

Fig. 3. Circuit of the Boost Rectifier when there are current in the phases $\mathrm{A}$ and $\mathrm{B}$.

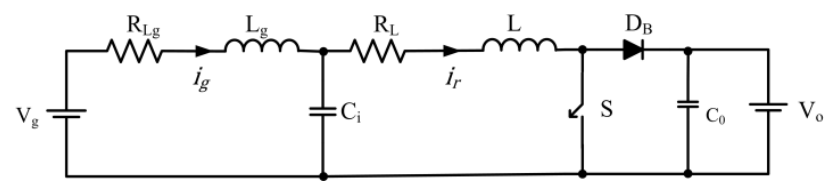

Fig. 4. Equivalent Circuit of the Boost Rectifier.

\section{B. Input filter}

An input LC filter is used to filter out the components at the switching frequency in the generator currents, and also to achieve DCM. Note that because of the large value of the generator inductances, the operation in DCM of the Boost Rectifier is not possible if an additional LC Filter is not used. Fig. 5 shows the equivalent circuit considering that $\mathrm{V}_{\mathrm{g}}=0$ at high frequency.

The transfer function from the rectifier current to the generator current is determined by (3).

$$
\frac{I_{g}(s)}{I_{r}(s)}=\frac{1}{s^{2} C_{i} L_{g}+s C_{i} R_{L g}+1}
$$

With $\mathrm{C}_{\mathrm{i}}=3.3 \mu \mathrm{F}$, an attenuation of $-44.3 \mathrm{~dB}$ at the switching frequency $\left(\mathrm{f}_{\mathrm{s}}=5 \mathrm{kHz}\right)$ is achieved by the filter. The Bode diagram of the filter is shown in Fig. 6.

\section{Average Current-Mode Control}

A small signal circuit of the Boost rectifier working in DCM can be obtained by means of the equivalent circuit of PWM switch [5], as it is shown by Fig. 7. The output voltage $\left(\mathrm{V}_{\mathrm{o}}\right)$ is regulated by the inverter connected to the power grid, so that the load that it is 'seen' by the Boost Rectifier can be modeled as a constant voltage source.

The values of the parameters of the PWM switch in DCM are shown by (4).

$$
\begin{aligned}
& g_{i}=\frac{D^{2} T_{s}}{2 L} \quad g_{o}=\frac{2 L P_{o}^{2}}{D^{2} V_{g}^{2} V_{o}^{2} T_{s}} \quad g_{f}=\frac{2 P_{o}}{V_{g} V_{o}} \\
& K_{i}=-\frac{D T_{s} V_{g}}{L} \quad K_{o}=-\frac{2 P_{o}}{D V_{o}}
\end{aligned}
$$

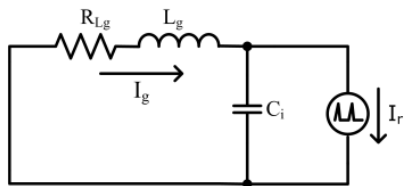

Fig. 5. Equivalent Circuit of the Boost Rectifier with input filter.

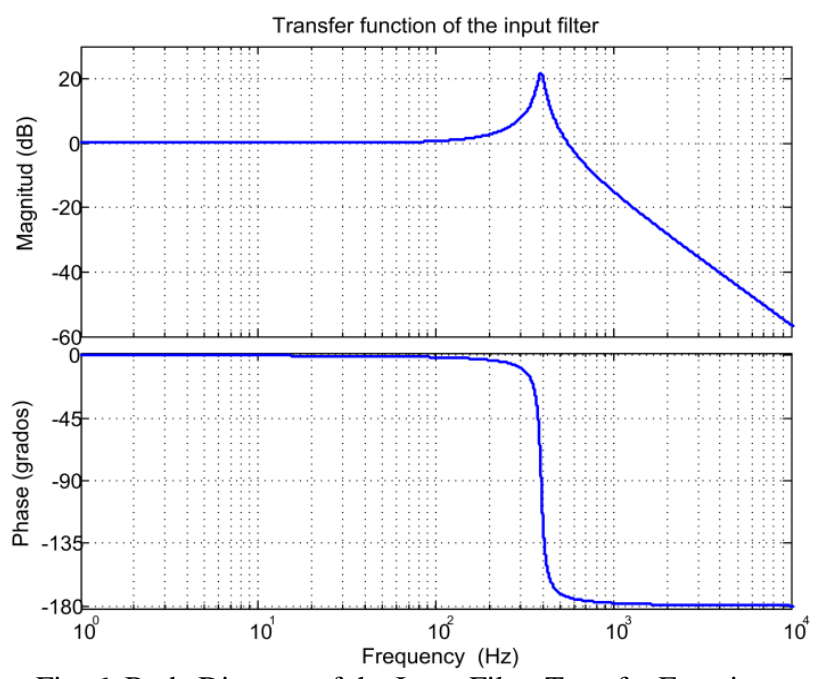

Fig. 6. Bode Diagram of the Input Filter Transfer Function $\mathrm{I}_{\mathrm{g}}(\mathrm{s}) / \mathrm{I}_{\mathrm{r}}(\mathrm{s})$.

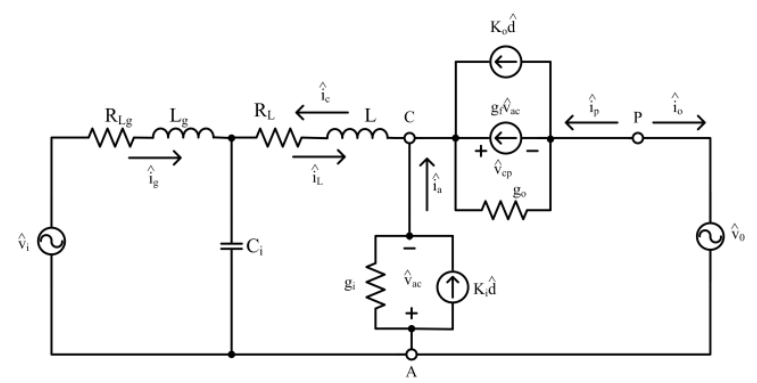

Fig. 7. Small Signal Equivalent Circuit of the Boost Rectifier with voltage source in the output.

The control loop structure of ACC [6] for this converter is shown by Fig. $8 . R_{i}$ is the current sense gain, $F_{M}$ is the modulator gain and $\mathrm{G}_{\mathrm{s}}(\mathrm{s})$ is the current compensator [6].

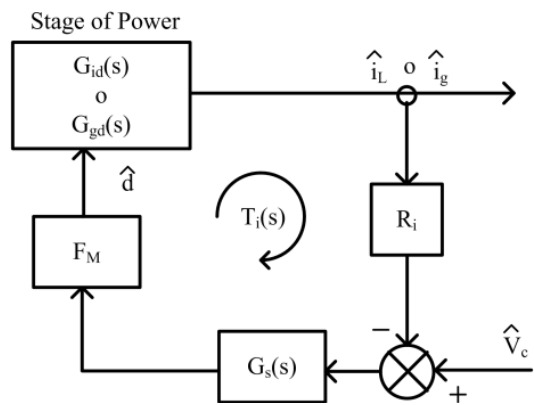

Fig. 8. Scheme of Average Current Mode Control.

In order to design the control loop, the duty cycle to Boost inductor current transfer function, $\mathrm{G}_{\mathrm{id}}(\mathrm{s})=$ $\mathrm{i}_{\mathrm{L}}(\mathrm{s}) / \mathrm{d}(\mathrm{s})$, is needed if the current loop is closed by sensing the Boost inductor current, this function is shown by (5).

$$
\begin{gathered}
G_{i d}(s)=\frac{\hat{\iota}_{L}(s)}{\hat{d}(s)}=\frac{-\left(s^{2} c_{i} L_{g}+s c_{i} R_{g}+1\right)\left(K_{i}+K_{o}\right)}{s^{3} B_{3}+s^{2} B_{2}+s B_{1}+B_{0}} \\
B_{3}=c_{i} L_{g} L\left(g_{i}+g_{o}+g_{f}\right) \\
B_{2}=c_{i}\left[L_{g}+\left(g_{i}+g_{o}+g_{f}\right)\left(L R_{L_{g}}+L_{g} R_{L}\right)\right] \\
B_{1}=\left[c_{i} R_{L_{g}}+\left(g_{i}+g_{o}+g_{f}\right)\left(L_{g}+L+c_{i} R_{L} R_{L_{g}}\right)\right] \\
B_{0}=\left(g_{i}+g_{o}+g_{f}\right)\left(R_{L_{g}}+R_{L}\right)+1
\end{gathered}
$$


As an alternative, the duty cycle to the generator currents transfer function, $\mathrm{G}_{\mathrm{gd}}(\mathrm{s})=\mathrm{i}_{\mathrm{g}}(\mathrm{s}) / \mathrm{d}(\mathrm{s})$, must be used if the current loop is closed by sensing the generator currents, this function is shown by (6).

$$
\begin{gathered}
G_{g d}(s)=\frac{\hat{g}_{g}(s)}{\hat{d}(s)}=\frac{\left(K_{i}+K_{o}\right)}{s^{3} B_{3}+s^{2} B_{2}+s B_{1}+B_{0}} \\
B_{3}=c_{i} L_{g} L\left(g_{i}+g_{o}+g_{f}\right) \\
B_{2}=c_{i}\left[L_{g}+\left(g_{i}+g_{o}+g_{f}\right)\left(L R_{L_{g}}+L_{g} R_{L}\right)\right] \\
B_{1}=\left[c_{i} R_{L_{g}}+\left(g_{i}+g_{o}+g_{f}\right)\left(L_{g}+L+c_{i} R_{L} R_{L_{g}}\right)\right] \\
B_{0}=\left(g_{i}+g_{o}+g_{f}\right)\left(R_{L_{g}}+R_{L}\right)+1
\end{gathered}
$$

The Bode plots of these transfer functions are shown by Fig. 9, with $\mathrm{L}=750 \mu \mathrm{H}$ and the values of the elements that have been previously presented. From this figure it may be deduced the convenience of measuring the generator currents instead of the DC current, because the resonance of the LCL filter difficult the control loop stabilization with practical crossover frequencies of the current loop.

The compensator $G_{s}$ (s) is designed to stabilize the current control loop, $\mathrm{T}_{\mathrm{i}}(\mathrm{s})$ with a phase margin larger than $50^{\circ}$ and a gain margin larger than $10 \mathrm{~dB}$.

With $\mathrm{V}_{\mathrm{i}}=562.57 \mathrm{~V}, \mathrm{~L}=750 \mu \mathrm{H}, \mathrm{P}=2 \mathrm{~kW}, \mathrm{~S}_{\mathrm{e}}=5 \mathrm{~V} / \mathrm{ms}$ and $\mathrm{R}_{\mathrm{i}}=0.1 \Omega$. The regulator $\mathrm{G}_{\mathrm{si}}(\mathrm{s})$ has been calculated for cascade compensation of $\mathrm{G}_{\mathrm{ic}}$ (s), following (7). The regulator $\mathrm{G}_{\mathrm{sg}}(\mathrm{s})$ has been calculated for cascade compensation of $\mathrm{G}_{\mathrm{gc}}(\mathrm{s})$, following (8).

$$
G_{s i}(s)=\frac{360\left(1+\frac{s}{1500}\right)}{s\left(1+\frac{s}{2500}\right)}=\frac{600(s+1500)}{s(s+2500)}
$$

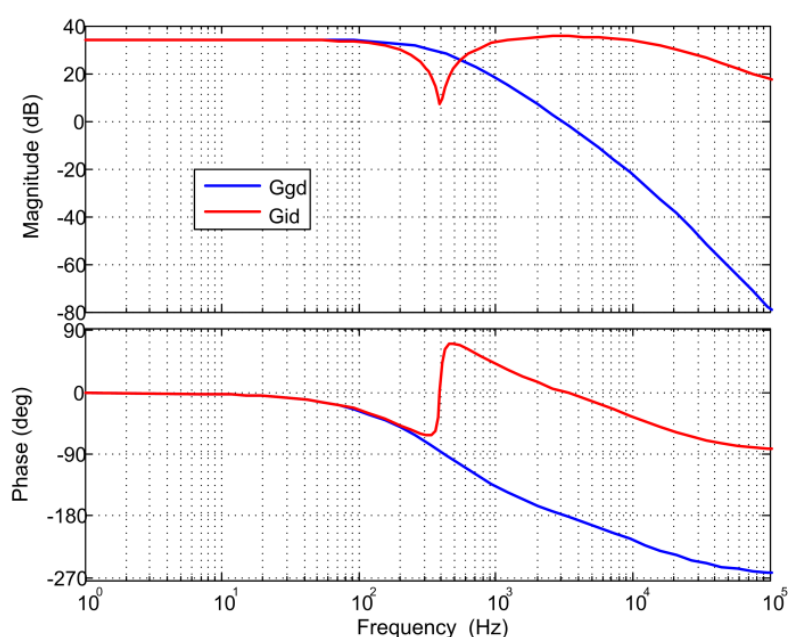

Fig. 9. Transfer Functions of the $\mathrm{G}_{\mathrm{ic}}(\mathrm{s})$ and $\mathrm{G}_{\mathrm{gc}}(\mathrm{s})$

$$
G_{s g}(s)=\frac{240\left(1+\frac{s}{1500}\right)}{s\left(1+\frac{s}{2500}\right)}=\frac{400(s+1500)}{s(s+2500)}
$$

After designing the input filter and the ACC controllers, we implement the system in PSIM to evaluate their large signal behavior. The ACC implementation when the current is measured directly in the DC side of the rectifier is shown by Fig. 10.

To close the ACC loop by measuring the generator currents, a signal processing is required to calculate the average value of the equivalent rectified currents of the generator.

The ACC scheme when the generator currents are measured, is shown by Fig. 11. Note that only two currents are sensed, because the PMSG currents are a balanced system. The signal processing has been implemented by means of a C Script Block of PSIM, in a similar way that it will be implemented in the experimental prototype.

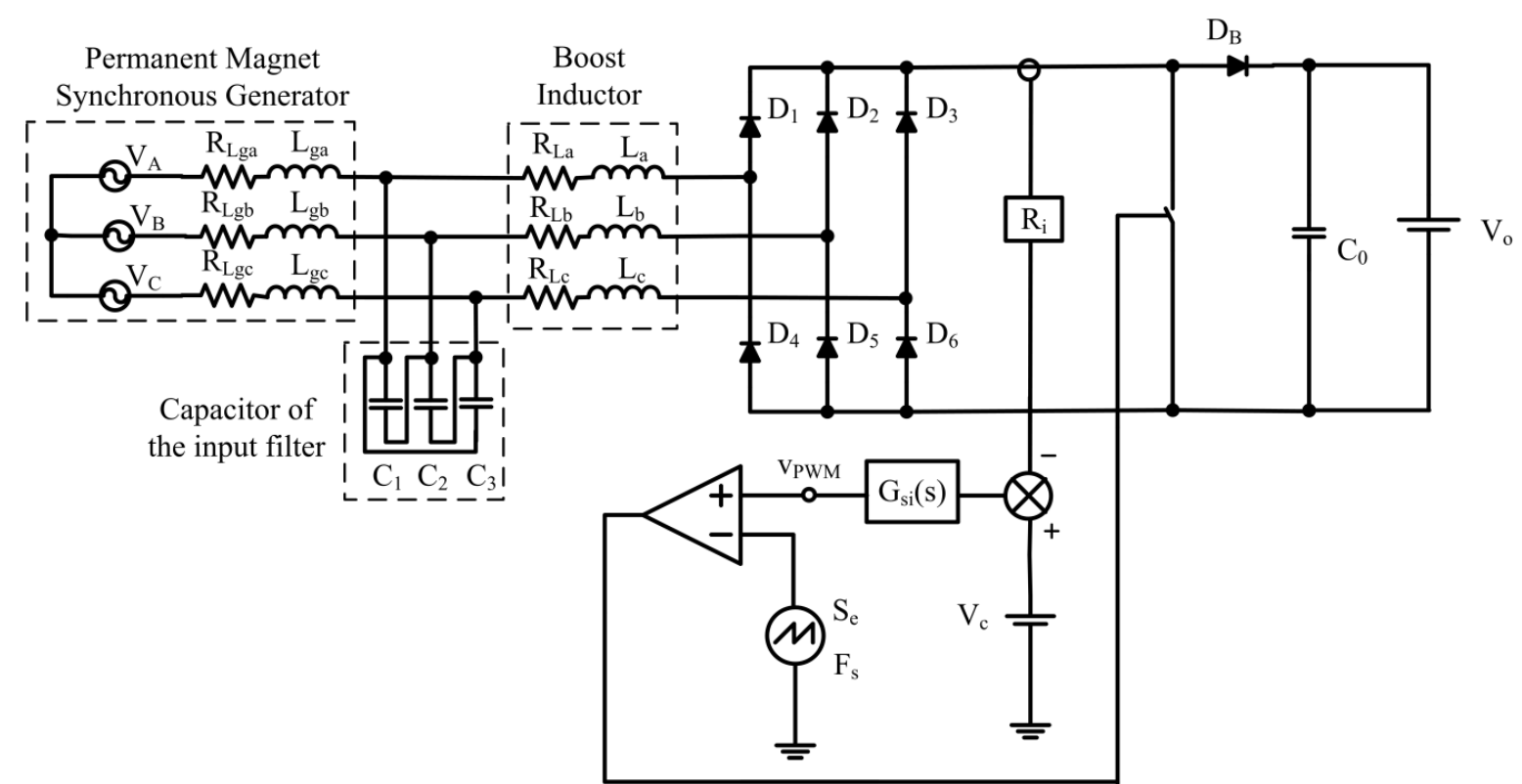

Fig. 10. Three Phase Boost Rectifier DCM with ACC Control and measuring directly in the DC side of the rectifier. 


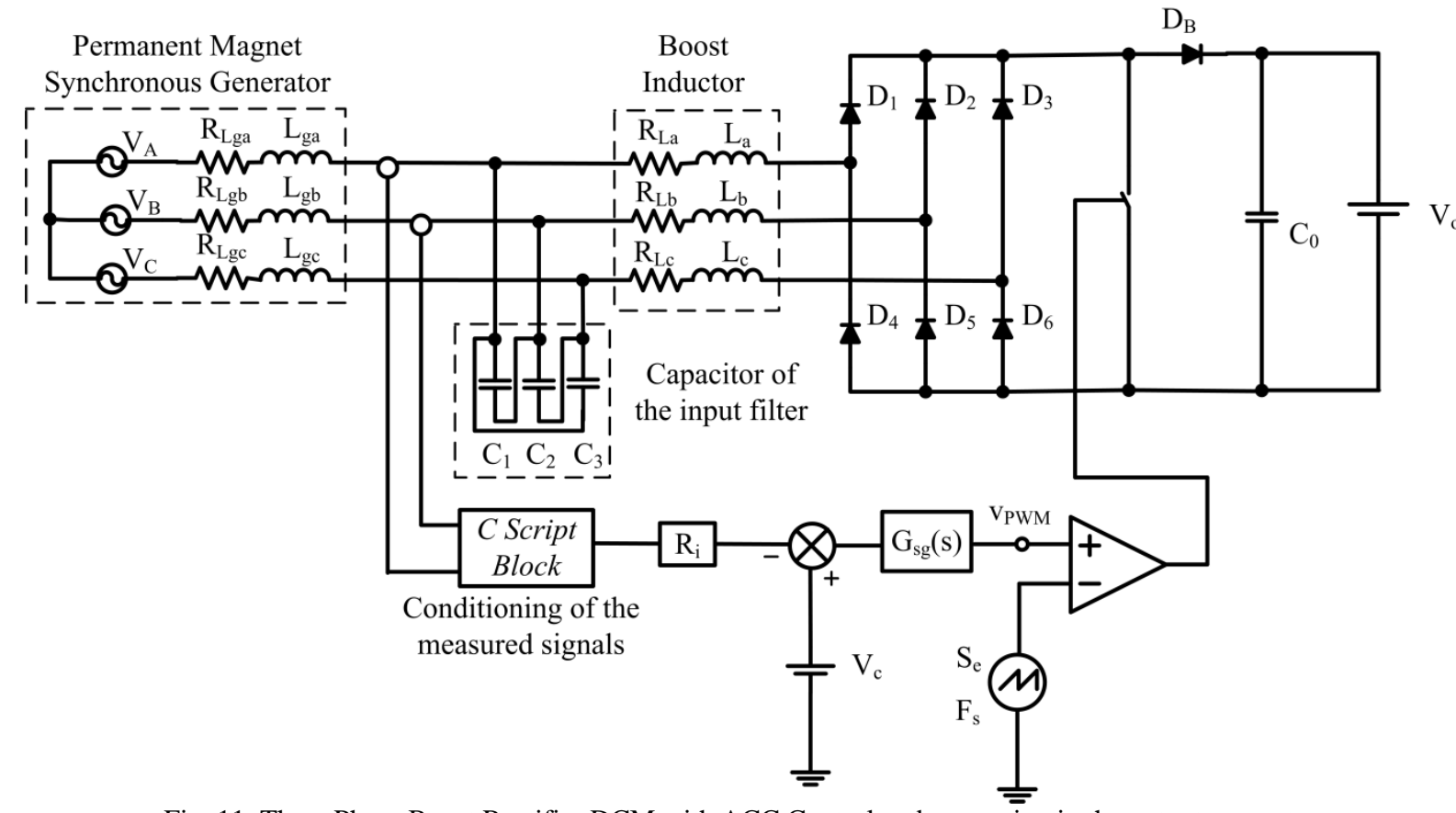

Fig. 11. Three Phase Boost Rectifier DCM with ACC Control and measuring in the output generator

The values obtained until moment are:

- Boost Inductance of one phase: $\mathrm{L}_{\mathrm{a}} \mathrm{L}_{\mathrm{b}}, \mathrm{L}_{\mathrm{c}}=375 \mu \mathrm{H}$

- ESR of the Boost inductors: $\mathrm{R}_{\mathrm{La}}, \mathrm{R}_{\mathrm{Lb},} \mathrm{R}_{\mathrm{Lc}}, \approx 100 \mathrm{~m} \Omega$.

- Capacitance of the filter: $\mathrm{C}_{1}, \mathrm{C}_{2}, \mathrm{C}_{3}=2.2 \mu \mathrm{F}$.

- Current sensing gain: $\mathrm{R}_{\mathrm{i}}=0.1 \Omega$.

- Slope of the PWM ramp: $\mathrm{Se}=5 \mathrm{~V} / \mathrm{ms}$.

\section{Results}

The performance of the proposed control loops have been evaluated by means of the PSIM 7.0.5 software [7].

Fig. 12 shows both current and voltage in one of the generator phases when the current is measured directly in the DC side of the rectifier.

Fig. 13 shows both current and voltage in one of the generator phases when the current is measured in the generator output.

Fig. 14 shows the measured generator $\mathrm{THD}_{\mathrm{i}}$ and $\mathrm{PF}$ of the PMSG in the whole speed operation range. The maximum power of the generator, which is limited by the nominal current at low speeds, is also shown.

In Fig. 14 it is shown that both $\mathrm{THD}_{\mathrm{i}}$ and $\mathrm{PF}$ significantly improve when the Boost Rectifier is operated in DCM, with regard to $\mathrm{CCM}$.

Note that the improvement of the THDi and PF values is better when the current is sensed directly at the output of the generator.
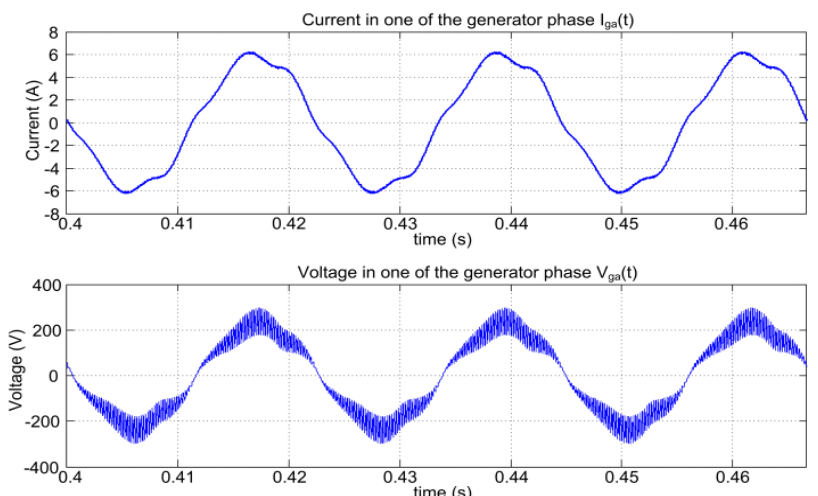

Fig. 12. Current and Voltage of one phase of a Three-Phase Boost Rectifier DCM with ACC Control when the current is measured directly in the DC side of the rectifier.
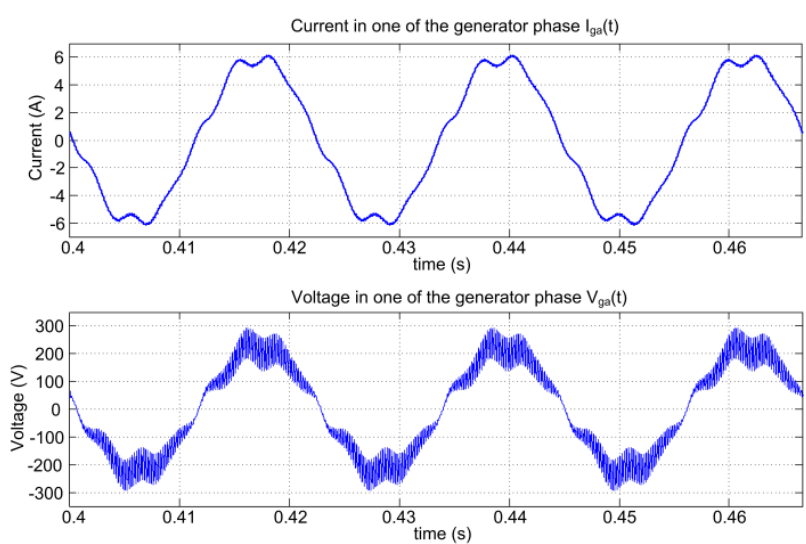

Fig. 13. Current and Voltage of one phase of a Three-Phase Boost Rectifier DCM with ACC Control when the current is measured in the generator. 

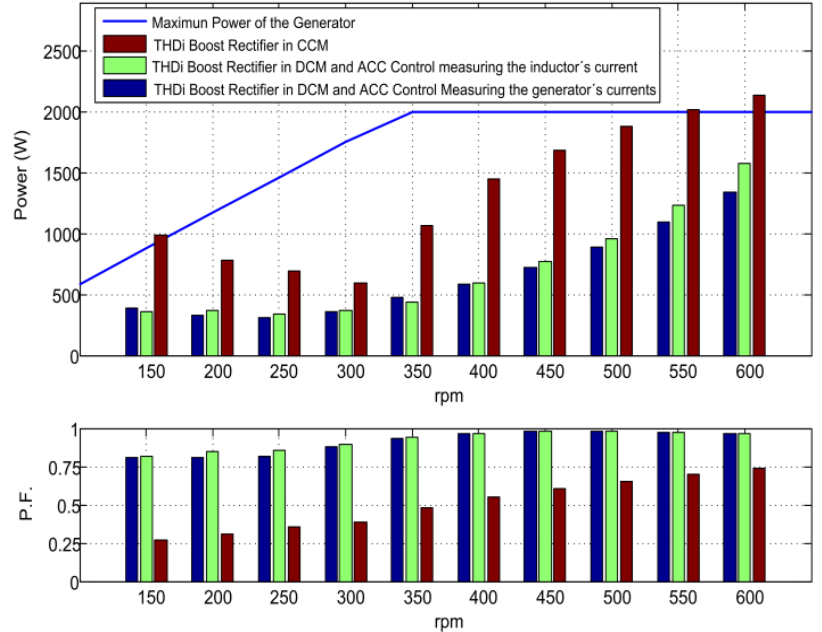

Fig. 14. Comparison of the measured THDi and PF in DCM and $\mathrm{CCM}$

\section{Conclusion}

In this paper it has been presented the application of average current mode control to a Three Phase Boost Rectifier applied to small wind turbines. In the implementation of the ACC control it has been devoted special attention in determining the most appropriate place to measure the current. From the analysis, it is obtained that the most appropriate place to measure the current is in the generator. With this, approach the rectifier achieves low $\mathrm{THD}_{\mathrm{i}}$ and a high $\mathrm{PF}$, in comparison with the Boost Rectifier operating in CCM.

A $2 \mathrm{~kW}$ prototype is currently been building-up to corroborate the data obtained in PSIM. The results will be compared by using peak current control (PCC). We will determine the advantages and disadvantages that present both current controls for this application.

\section{Acknowledgement}

The first author thanks the support of the National Polytechnic Institute (IPN) and of the Commission of Operation and Promotion of Academic Activities (COFAA) to finances his stay in the Polytechnic University of Valencia (UPV).

\section{References}

[1] A. R. Prasad, P. D. Ziogas, S. Manias, "An Active Power Factor Correction Technique for Three-Phase Diode rectifiers" IEEE Trans. on Power Electronics, vol. 6, no. 41, pp. 83-92, January 1991.

[2] Y. Jang, M. M. Jovanovic, "A New Input-Voltage Feedforward Harmonic-Injection Technique Nonlinear Gain Control for Single-Switch, Three-Phase, DCM Boost Rectifiers" IEEE Trans. on Power Electronics, vol. 20, no. 1, pp. 268-277, March 2000.

[3] P. Barbosa, F. Canales, J. C. Crebier, F.C. Lee, "Interleaved Three-Phase Boost Rectifiers Operated in the Discontinuous Conduction Mode: Analysis, Design Considerations and Experimentation" IEEE Trans. on Power Electronics, vol. 16, no. 5, pp. 724-734, September 2001.
[4] Robert W. Erickson, Dragan Maksimovic, Fundamentals of Power Electronics, USA, Kluwer Academic Publishers, 2001.

[5] V. Vorperian, "Simplified analysis of PWM converters using model of PWM switch I and II" IEEE Trans. on Aerospace and Electronic Systems, vol. 26, no. 3, pp. 490505, may 1990.

[6] W. Tang, F. C. Lee, R. B. Ridley, "Small-Signal Modeling of Average Current-Mode Control", IEEE Trans. on Power Electronics, vol. 8, no. 2, pp. 112-119, April 1993.

[7] PSIM 7.0 User's Guide (2006), Powersim Inc., March 2006. 